\title{
The prevalence of waterpipe tobacco smoking among Polish youths
}

Wioleta Zielińska-Danch

Department of General and Inorganic Chemistry, School of Pharmacy with the Division of Laboratory Medicine, Medical University of Silesia, Katowice, Poland

Submitted: 3 January 2018; Accepted: 3 April 2018;

Online publication: 21 May 2019

Arch Med Sci 2021; 17 (3): 731-738

DOI: https://doi.org/10.5114/aoms.2019.84487

Copyright (C) 2019 Termedia \& Banach

\section{Abstract}

Introduction: Waterpipe smoking is gaining popularity among the youth in Poland and is evaluated for the first time in this work. The authors address the social and demographic factors that motivate young people to smoke and attempt to determine which of them contribute to habit formation.

Material and methods: The data were collected among school and university students in Poland during a global survey on various forms of tobacco use. Multivariable regression models were applied for odds-ratio evaluation. The data concern waterpipe and cigarette smoking habits.

Results: The survey was completed by 19,097 respondents. The survey included 144 schools and 32 universities from 16 voivodeships in Poland. Respondent gender exhibited the highest ORs $(95 \% \mathrm{Cl})$, both in the case of current and ever WP users: 2.11 (2.10-2.12) and 2.16 (2.15-2.17), respectively. The other important factor was a place of living: $1.83(1.82-1.84)$ and 2.17 (2.16-2.18), respectively. All ORs were statistically significant for $p=0.05$.

Conclusions: The prevalence of tobacco smoking among Polish youths is high. Waterpipe tobacco smoking was found to be the second most popular habit after cigarette smoking. Moreover, young smokers use other non-tobacco products in waterpipes, and drink alcohol during smoking sessions. Many young people try waterpipe smoking without previous experience with cigarettes.

Key words: adolescents, tobacco smoke, waterpipe smokers.

\section{Introduction}

Tobacco use is a global problem due to its prevalence and harmful impact on society and economic activity. Tobacco can be used in products subject to smoking, chewing, or snuffing. A waterpipe (WP) may be used for the smoking option. The use of WPs (narghile, hookah, shisha) has rapidly risen in popularity in the last decade. Waterpipes come from the Eastern Mediterranean, but are gaining popularity in Europe, North America, and Australia. Studies aiming to identify the physical properties and effects of WP smoke have been conducted for years and are still expanding [1-4]. Although tobacco-free alternatives are used in WP, waterpipe tobacco smoking (WTS) is treated as an "epidemic". It has replaced cigarettes and is the most popular form of tobacco use among youths in the Middle East. In other countries it is becoming the second most popular form, after cigarettes [5-7]. It was shown that WP smoke contains significant concentrations of the same toxicants as cigarette

\author{
Corresponding author: \\ Wioleta Zielińska-Danch \\ Department of General \\ and Inorganic Chemistry \\ School of Pharmacy \\ with the Division \\ of Laboratory Medicine \\ Medical University \\ of Silesia in Katowice \\ 4 Jagiellońska St \\ 41-200 Sosnowiec, Poland \\ E-mail: wzdanch@sum.edu.pl
}


smoke $[2,3,8,9]$. The literature also describes the content of WP smoke from sweetened, flavoured, tobacco-free alternatives [2]. The rapid increase in the interest and popularity of WP smoking has been attributed to the following factors [7]: (a) the pleasant flavour and aroma; (b) a misperception of "healthy" smoking; (c) the social aspect of smoking; (d) mass and social media advertising; (e) a lack of policy concerning WP smoking; and $(\mathrm{f})$ the migration of peoples. Contrary to misconceptions about WP smoking being safe, there are several short- and long-term effects [3, 4, 10]. Moreover, a growing body of literature gives evidence that WTS is conducive to dependence on nicotine/tobacco [11]. However, some authors indicate that this is because WP use among friends or family is socially and culturally acceptable. It was shown in the survey that Near- or Middle-Eastern ethnic origins, as well as having friends from these regions, are significant predic tors of WP use among US students [12]. Waterpipe smoking is rather a social habit, and friends staying in one place smoke from a single WP. Very often, this takes place in a public venue intended for WP smoking. Considerable variety in venue characteristics and smoking behaviours between groups in different countries was observed $[13,14]$. Air measurements taken at the venues featured in the study showed concentrations of carcinogenic substances similar or greater to those typically found in venues in which cigarettes are smoked. Employees and customers were more exposed to carcinogens in the venues without ventilation systems, air conditioning, or outdoor areas [13].

Waterpipe use requires specific legislation to address unique challenges. This prospect is complicated by the existence of harmful "non-tobacco" substitutes, which are excluded from tobacco control laws and are sold and consumed by WP smokers. A review of legislation from 62 countries [15] showed that most of them do not regulate the smoking of waterpipe tobacco or non-tobacco. Moreover, there is no clear message, especially to young people, about the harmful effects of WP smoking. In Europe, the habit of WP smoking is present mainly among young people, who are always looking for new sensations [6]. Although marketing activities are directed towards adults $[16,17]$, especially the more aggressive advertising activities, they also contribute to the increase in interest among young people, who are naturally more receptive to new ideas and alternative solutions. The accessibility of WPs to young people is unregulated, which is a worrying fact. Despite reports on the harmful effects of smoking on the cardiovascular system, reduced lung function, and nicotine addiction [18], the impact of WPs on public health remains commonly unknown, mainly due to the frequency of WP use and the substanc- es smoked. At present, WP smokers are primarily youths, i.e. university and college students [19-22] and high school students [5, 6, 23-25].

The total population of Poland is estimated to be 38.2 million, with $14.7 \%$ aged 15 to 24 years [26]. Recent data show that $30.3 \%$ (9.8 million) of the population aged 15 years and above smoke cigarettes (36.9\% male and $24.4 \%$ female) [27]. The Global Youth Tobacco Survey showed that $18.6 \%$ of Polish students aged 13-15 years engaged in tobacco use. The percentage was higher among boys than among girls in 2003 (19.6\% vs. $17.1 \%$, respectively) [28]. Documentation on the progress of tobacco control in Poland $[29,30]$ describes legislative and other efforts, which have significantly improved the health situation in the country. However, there is no data on the prevalence of WTS, or the reasons for its popularity.

The goal of this work is to estimate the scale of the phenomenon in Poland. Research was focused on demographic distribution and the predictors of WP use. This paper addresses the social and demographic factors that motivate young people to smoke and attempts to determine which of them contribute to habit formation. It seems that a cross-sectional survey with an adequate questionnaire is a good tool for data collection among young people. This approach let us collect opinions, which can be developed using statistical models [31]. This paper also addressed the use of non-tobacco products.

\section{Material and methods}

\section{Data collection}

The data were collected among teenagers and young people in Poland, i.e. students of secondary schools and universities, during a global survey on tobacco smoking in various forms. The study did not take into account secondary art schools, special education centres, or art universities. In the first stage, the study was performed only in the Silesia region to determine the clarity of the content, the understandability of the questions, the time required to fill out the questionnaire, as well as data collection and management procedures. In the second stage, from September 2010 to the end of 2011, a global study was performed in Poland. The selection of school students (SS) and university students (US) was narrowed down in three steps. First, three localities were chosen from each of the 16 voivodeships. One of the chosen localities was always the capital of the voivodeship. Second, 11 schools and three universities were chosen within the localities. Third, 115 randomly selected students from each school were invited to participate in the study. The expected sample size was 20,240 SS and 5,520 US (25,760 total). The same research process was described in detail in a previous paper [32] 
which only addressed the smoking of e-cigarettes. It should be mentioned here that some parts of the questionnaires were returned blank or incomplete.

\section{Questionnaire}

The questionnaire was in Polish and consisted of 90 closed questions that addressed the demographics of the respondents (age, sex, place of residence, family size) and their history of using various forms of tobacco (cigarettes, waterpipes, snuff, chewing tobacco, and e-cigarettes). The questions about waterpipes concerned the circumstances of use, the age at which they began using, the reasons for continued use, and the frequency of use. Additionally, the respondents answered the questions about the venues, reasons, and circumstances of WP smoking, the most frequent venue for WP smoking, the duration of an average session, and the type of tobacco or other psychoactive substances used. Other questions were related to alcohol consumption, the hygiene of smoking (use of disposable mouthpieces), the use of additives (advertised as reducing the toxicity of smoke), the influence of WP smoking on mood, and willingness to stop smoking. Some of the questions dealt with respondents' general opinions on smoking (non-smoking areas, age restrictions, etc.). The respondents were asked about their visitation of venues where smoking is not prohibited. The questions also concerned the smoking habits of the respondents' parents and partners (in the case of adult participants). The questionnaire was divided into seven groups of questions.

\section{Legal conditions}

The questionnaire was reviewed by the Committee for Human Research, and the study procedure was conducted in accordance with the requirements of the Medical University of Silesia (Poland). The authors obtained permission to perform the study from the competent supervisory authorities in each region (i.e. the superintendents of education and school directors). Participation in the study was voluntary, anonymous, and confidential. All participants verbally consented to participation and could cease participation at any time or refuse to answer any question without reason.

\section{Statistical analysis}

Statistical analysis was performed using Statistica (StatSoft, ver. 10). Due to the disproportionality of the tested groups, we introduced weights to achieve the actual representativeness of the samples at the national level, as well as with regard to province, city/village, school/university, and sex. The weights were constructed using the Demographic Yearbook 2010, published by the Central Statistical Office in Poland [26].
To assess multivariable associations, we performed a multiple logistic regression analysis to determine the extent to which certain factors affected the outcome. Odds ratios (OR) were given with a 95\% confidence interval (CI). For all analyses, $p \leq 0.05$ were considered statistically significant.

\section{Results}

\section{Tobacco use}

Representative samples of 15-19-year-old school students and 20-25-year-old university students were selected. Use of various forms of tobacco and its substituents (e-cigarettes) was declared by $68.3 \%$ of the respondents (the percentage was calculated for the whole studied population of school and university students). A detailed distribution of tobacco products used by the two groups of young people is shown in Figure 1. The horizontal bars indicate the percentage of users. The numbers within the parentheses give the percentage of users calculated with the appropriate weights for the groups. As many as 67.6\% of the respondents had tried cigarettes. Regular smokers, i.e. those who had smoked every day for the last 30 days and who had smoked at least 100 cigarettes in their lives, accounted for $35.5 \%$ of the respondents. Students smoking less than five cigarettes per day (53.3\%) were dominant among regular smokers; while $33.5 \%$ smoked 5-15 cigarettes a day. More than a quarter $(27.7 \%)$ declared smoking a cigarette $0.5 \mathrm{~h}$ after getting out of bed. The most common forms of regular tobacco use among young Poles (weighted values) are cigarette smoking (34.2\%), WTS (22.7\%), and snuff (16.9\%). The most common forms of trial tobacco use are cigarette smoking (68.4\%), WTS (45.7\%), and snuff (36.1\%).

\section{WTS sociodemographic characteristics}

The survey was completed by 19,097 respondents (16,187 school students and 2,910 university students). The response rate was $74.1 \%$. A total of 144 schools and 32 universities took part in the survey from all 16 voivodeships in Poland. It should be emphasised that for multivariable analysis, we only accounted for the questionnaires that were fully completed. $3.9 \%$ of our samples lacked data on WP use or lack thereof and were thus excluded from the fully adjusted multivariable analysis presented here. Women accounted for $54.9 \%$ of the studied population; $2.8 \%$ did not indicate their sex. More than half of the respondents (59.6\%) were from urban areas. Most of the respondents (85.2\%) lived with their parents, and $50.6 \%$ had parents who smoked cigarettes (both parents -3020 , only one parent -4138 , unindi- 


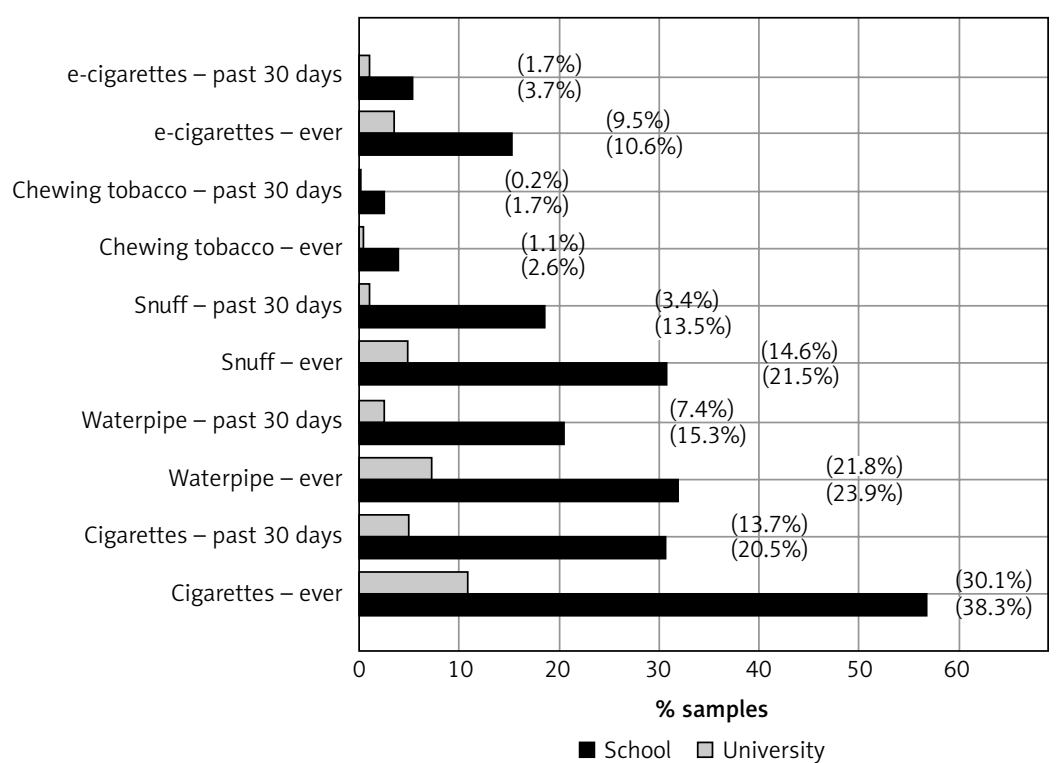

Figure 1. Distribution of tobacco products taken by two groups (school and university students) of young people $(n=19,097)$. The numbers in parentheses give the weighted value

cated - 298). The number of respondents in all the analysed groups was always higher than the number of actual participants, providing a statistical error of $3 \%$ (confidence interval $95 \%(\mathrm{Cl})$ ). The sociodemographic data are presented in Table I.
Current (past 30 days) or ever WP use was associated with age (school or university students), sex, place of residence, residence with parents, and residence with parents who smoke. In a fully adjusted multivariable model, the OR for ever

Table I. Sociodemographic data of waterpipe users; odds ratios and confidence intervals (Cl) from logistic regression. The numbers in parentheses given in the columns for the ever and the current waterpipe smokers present the percentage of smokers calculated in relation to the appropriate group

\begin{tabular}{|c|c|c|c|c|c|}
\hline $\begin{array}{l}\text { Sociodemographic } \\
\text { data }\end{array}$ & $\begin{array}{c}\text { Whole } \\
\text { sample, } \\
n=19,097 \\
(\%)\end{array}$ & $\begin{array}{l}\text { Waterpipe - } \\
\text { ever, } \\
n=7418 \\
(\%)\end{array}$ & $\begin{array}{l}\text { Adjusted } \\
\text { odds ratio } \\
(95 \% \mathrm{Cl})\end{array}$ & $\begin{array}{c}\text { Waterpipe - } \\
\text { past } 30 \text { days, } \\
n=4352 \\
(\%)\end{array}$ & $\begin{array}{l}\text { Adjusted } \\
\text { odds ratio } \\
(95 \% \mathrm{Cl})\end{array}$ \\
\hline \multicolumn{6}{|l|}{$\begin{array}{l}\text { Age } \\
\text { (school grade): }\end{array}$} \\
\hline 15-19 years (school) & 84.7 & $81.8(37.5)$ & Reference & $89.2(24.0)$ & Reference \\
\hline \multirow[t]{2}{*}{$20-25$ years (university) } & 15.2 & $18.2(46.3)$ & $1.31(1.18-1.45)$ & $10.8(16.1)$ & $0.60(0.53-0.69)$ \\
\hline & & & $1.30(1.29-1.31)^{\star}$ & & $0.54(0.53-0.54)^{\star}$ \\
\hline \multicolumn{6}{|l|}{ Gender: } \\
\hline Female & 54.9 & $43.6(30.9)$ & Reference & $38.7(16.1)$ & Reference \\
\hline \multirow[t]{2}{*}{ Male } & 42.3 & $53.0(48.7)$ & $2.22(2.08-2.36)$ & $57.5(31.0)$ & $2.27(2.11-2.44)$ \\
\hline & & & $2.16(2.15-2.17)^{\star}$ & & $2.11(2.09-2.12)^{*}$ \\
\hline \multicolumn{6}{|l|}{ Area of living: } \\
\hline Rural & 40.4 & $28.6(27.5)$ & Reference & $29.8(16.8)$ & Reference \\
\hline \multirow[t]{2}{*}{ Urban } & 59.6 & $71.4(46.6)$ & $2.23(2.09-2.38)$ & $70.2(26.8)$ & $1.85(1.72-2.00)$ \\
\hline & & & $2.17(2.16-2.18)^{\star}$ & & $1.83(1.82-1.84)^{\star}$ \\
\hline \multicolumn{6}{|l|}{ Living with parents: } \\
\hline No & 14.4 & $17.1(45.9)$ & Reference & $12.2(19.3)$ & Reference \\
\hline \multirow[t]{2}{*}{ Yes } & 85.2 & $82.5(37.6)$ & $0.76(0.68-0.84)$ & $87.4(23.4)$ & $0.89(0.79-1.01)^{\mathrm{N}}$ \\
\hline & & & $0.68(0.68-0.69)^{*}$ & & $0.71(0.70-0.71)^{*}$ \\
\hline \multicolumn{6}{|l|}{ Parents smoking: } \\
\hline No & 47.8 & $45.3(36.8)$ & Reference & $42.8(23.4)$ & Reference \\
\hline \multirow[t]{2}{*}{ Yes } & 50.6 & $53.3(40.9)$ & $1.22(1.15-1.30)$ & $55.4(25.0)$ & $1.28(1.20-1.38)$ \\
\hline & & & $1.13(1.12-1.13)^{*}$ & & $1.17(1.17-1.18)^{*}$ \\
\hline
\end{tabular}

${ }^{N}$ Not statistically significant, *weighted values. 
users was higher for males 2.22 (2.08-2.36), those residing in urban areas 2.23 (2.09-2.38), those residing away from their parents $0.76(0.68-0.84)$, university students 1.31 (1.18-1.45), and those residing with parents who smoke 1.13 (1.12-1.13). The OR for current users was higher for males 2.27 (2.11-2.44), those residing in urban areas 1.85 (1.72-2.00), school students 0.60 (0.53-0.69), those residing with parents who smoke 1.29 (1.201.38), and those residing away from their parents 0.89 (0.79-1.02) (this value is not statistically significant). In fully adjusted multivariable weighted models, current and ever WP use was associated with the same factors mentioned for the unweighted analysis. The individual factor most strongly associated with the highest ORs was sex (male), both in the case of current and ever WP users. The values were $2.11(2.10-2.12)$ and 2.16 (2.15-2.17), respectively. The data marked with a star were obtained for the adjusted multivariable analysis, performed with weights appropriate for each group studied.

\section{WTS and other drug characteristics}

Waterpipes smoking was the second most popular form of smoking after cigarette smoking among young Poles. In the survey, as many as $38.9 \%$ of the respondents had smoked a WP at least once, and $22.8 \%$ of the respondents declared smoking regularly $(59.8 \%$ male and $37.4 \%$ female) "because they like it" (35.6\%) and "to relax" (32.7\%). $37.7 \%$ of them were WP smokers who also smoked cigarettes. $45.8 \%$ of the respondents declared smoking a WP for the first time in lower secondary school (13-15 years old), and $44.7 \%$ in secondary school (16-19 years old). As many as $5.1 \%$ began to smoke WPs in primary school. Contrary to cigarette smokers, WP smokers are mostly occasional smokers (54.5\%), but $4.3 \%$ of WP smokers reported that they use it every day.
Almost all WP smokers (94.2\%) started smoking in the company of friends who smoke. $70.1 \%$ of WP smokers began smoking out of curiosity, including $20 \%$ due to the company they kept. More than a quarter of WP smokers (27.3\%) did not give any reason for smoking. More than half of the respondents (64.8\%) participated in sessions lasting up to $1 \mathrm{~h}$, and $23 \%$ participated in longer sessions (1-2 h). Most declared smoking mo'assel tobacco (68.1\%). Only $22.7 \%$ used a personal mouthpiece when smoking.

The respondents who currently use WP (4352) also provided data on the use of drugs and alcohol. More than half of them (52.6\%) drank alcohol during smoking sessions. Additionally, they smoked cigarettes (58.9\%), marihuana (42.1\%), and hashish (38.3\%) and used other drugs (33.7\%). All of the WP users who declared marihuana use (1774) also used other drugs (Venn diagram for weighted values in Figure 2). For the groups of school and university students (group $A$ and $B$ in Figure 2, respectively), the diagrams show what percentages declared the use of other drugs. When smoking marihuana in a WP, the vast majority of school and university students also used other illegal drugs (hashish, crack, and designer drugs).

\section{Perception of tobacco products}

Research shows a high awareness among young people of the harmful effects of smoking, but this is always associated with cigarettes. As many as $90.5 \%$ of WP smokers are of the opinion that cigarette smoking is unhealthy, and $80.5 \%$ believe that second-hand smoking has a negative effect on their health. The same people, however, show a lack of basic knowledge concerning the health effects of WP smoking. As many as 44.7\% did not know that WP smoking supplies nicotine to the body, or they believed that WP tobacco did
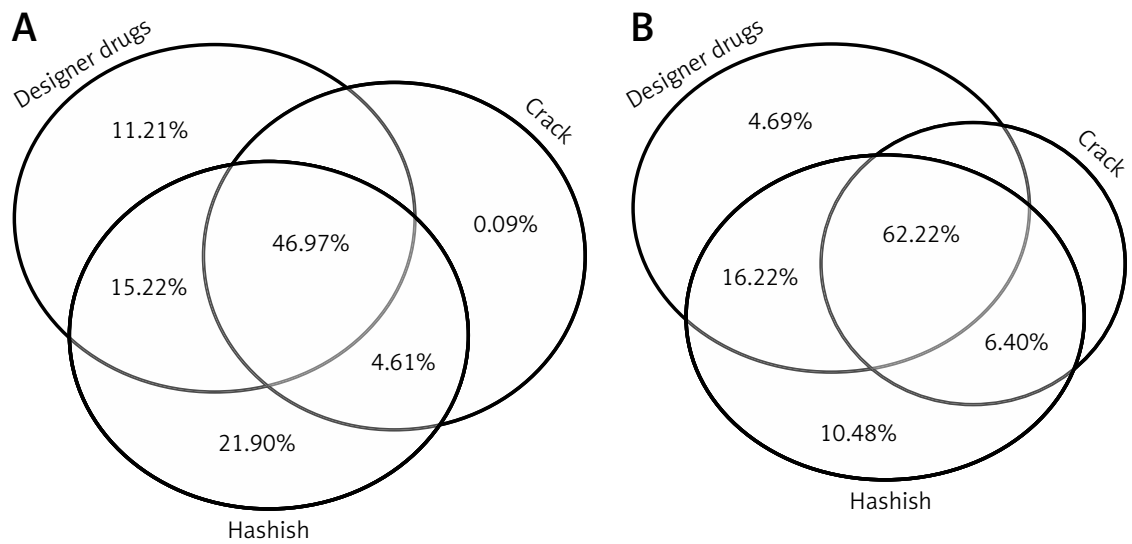

Figure 2. The percentage use of other drugs for the group of school (A group) and university students (B group), smoking marihuana in a waterpipe 
Table II. Perception of tobacco smoking, odds ratios, and confident intervals from logistic regression

\begin{tabular}{|c|c|c|c|c|c|}
\hline Characteristics & $\begin{array}{l}\text { Whole sam- } \\
\text { ple, } \\
\begin{array}{c}n=19,097 \\
(\%)\end{array}\end{array}$ & $\begin{array}{c}\text { Waterpipe - } \\
\text { ever, } \\
\begin{array}{c}n=7418 \\
(\%)\end{array}\end{array}$ & $\begin{array}{l}\text { Adjusted } \\
\text { odds ratio } \\
(95 \% \mathrm{Cl})\end{array}$ & $\begin{array}{c}\text { Waterpipe - } \\
\text { past } 30 \text { days, } \\
n=4352 \\
(\%)\end{array}$ & $\begin{array}{l}\text { Adjusted } \\
\text { odds ratio } \\
(95 \% \mathrm{Cl})\end{array}$ \\
\hline \multicolumn{6}{|c|}{ Do you think that WTS is less harmful than cigarette smoking? } \\
\hline No & 19.0 & 18.8 & Reference & 18.3 & Reference \\
\hline Yes & 36.3 & 57.6 & $2.90(2.66-3.16)$ & 60.9 & $2.34(2.13-2.57)$ \\
\hline Don't know & 42.9 & 22.4 & $0.63(0.58-0.69)$ & 19.7 & $0.59(0.53-0.66)$ \\
\hline \multicolumn{6}{|c|}{ Do you think that WTS delivers nicotine? } \\
\hline No & 11.1 & 15.6 & Reference & 17.4 & Reference \\
\hline Yes & 40.5 & 54.3 & $1.13(1.02-1.25)$ & 54.3 & $0.94(0.85-1.44)^{\mathrm{N}}$ \\
\hline Don't know & 46.8 & 29.1 & $0.46(0.42-0.52)$ & 27.3 & $0.47(0.42-0.53)$ \\
\hline \multicolumn{6}{|c|}{ Does WTS affect your mood during a party? } \\
\hline No & 69.7 & 54.1 & Reference & 51.1 & Reference \\
\hline Yes & 29.3 & 45.2 & $3.21(3.00-3.43)$ & 48.4 & $2.83(2.63-3.04)$ \\
\hline \multicolumn{6}{|c|}{ Does WTS help you to socialise? } \\
\hline No & 79.9 & 72.9 & Reference & 71.9 & Reference \\
\hline Yes & 19.5 & 26.6 & $1.48(1.36-1.60)$ & 27.6 & $1.34(1.24-1.46)$ \\
\hline
\end{tabular}

${ }^{N}$ Not statistically significant, $\mathrm{Cl}$ - confidence interval.

not contain nicotine (even though the tobacco is smoked in a pipe). More than a half of them (57.6\%) believed that WP smoking was less harmful than smoking cigarettes, and as many as $22.4 \%$ had no knowledge on the subject (Table II). More than half of the respondents (53.1\%) declared that they were irritated by cigarette smoke; however, in spite of this, they would go to places where WPs were smoked, citing the nice fragrances as an attraction. Moderate discomfort did not dissuade respondents from smoking $(19.2 \%$ declared nausea and vertigo after a session of WP smoking). About $27 \%$ of WP smokers believe that smoking helps to establish and maintain friendships, and $45.2 \%$ of them believe that smoking has a beneficial effect on their mood during sessions. This is the reason why many smokers visit venues where WP smoking is allowed (36.4\%). Only $20.3 \%$ of WP smokers had participated in an anti-smoking program within the last year. Only $6.3 \%$ of the respondents declared a willingness to quit WP smoking, and $65.0 \%$ of the smokers thought that they smoke only occasionally and therefore do not need to quit.

\section{Discussion}

Cigarette smoking was significantly more common than WP smoking among university students (17.0\% and $9.9 \%$, respectively). Among school students, the prevalence of both habits was similar (17.0\% and $12.6 \%$, respectively). In both student groups, the prevalence of smoking habits was rather low as compared with the appropri- ate groups of "ever" smokers (Figure 1). Youths smoke cigarettes more often and stick with this form of tobacco consumption. The percentage of users of tobacco in other forms is rather low (except for snuff $-11.0 \%$ ) but is worthy of a mention. Although there is a rather large disproportion between ever and current users, which would indicate that smoking is becoming less attractive, the number of current young smokers seems to be exceptionally high.

Waterpipes smoking is the second most popular form of tobacco consumption among young Poles nowadays. The dominant profile of a young WP smoker in Poland is a male residing in an urban area, 15-19 years old (school student), who resides away from his parents, and whose parents smoke cigarettes. The dominant profile of a previous WP smoker is a male residing in an urban area, 20-25 years old (university student), who resides away from his parents, and whose parents smoke cigarettes. The perceived harmlessness of WP smoking is presumably the main reason for smoking. Most of the respondents declared that WP smoking is less harmful than cigarette smoking. Moreover, they thought that WTS did not contain nicotine. However, this is hard to believe in an era of general access to information. One can find that the young people do not believe that smoking impacts their mood during a party, especially if we take into account the answers to the question of whether WTS helped respondents to socialise. This would mean that either the respondents were not aware of the influence of WTS on them, that they engaged in WP smoking with a group of 
well-known people, or that WP smoking was an aim in end of itself. These aspects of WP use will be discussed in a separate paper.

Smoking of marihuana in WPs by young people was associated with the use of other drugs. In both age groups, a significant percentage of respondents (46.9\% - SS, $62.2 \%$ - US) smoked all the drugs studied. Additionally, they drank alcohol during smoking sessions.

We can find new trends in the population studied. Several years ago, the only form of tobacco use was cigarette smoking. In recent years, there has been a revolution in the thinking of young people that strongly influences their behaviour. The data from 2010 showed [27] that $30.3 \%$ of the population aged $15+$ smokes cigarettes. Furthermore, our own study shows that $22.7 \%$ of students are WP smokers (15-25 years old, Figure 1, past 30 days), and that the number of men/boys who smoke WP is almost two times higher than that of women/ girls (31.0\% and $16.1 \%$, respectively, Table I), where $34.2 \%$ of the total population are cigarette smokers. There are no previous data concerning WP smokers in Poland, making an adequate comparison impossible. However, such a comparison can be made with other countries, mainly in the Middle East [5]. The prevalence of WP smoking among male secondary school students was as follows: Lebanon - 25\%; Saudi Arabia - 9\%. Among male university students, these percentages were $28 \%$ and $8 \%$, respectively. In Pakistan, this percentage was 33\% among university students (not including females). The data for school and university students in the USA (with a high percentage of Middle Eastern descent) showed that these proportions were $12 \%-15 \%$ and $5 \%-8 \%$, respectively. This was lower for university students in Estonia, i.e. $21 \%$ and $8 \%$, respectively. The prevalence of WP smoking among Polish students is similar to that in the countries mentioned above, namely $15.3 \%$ (SS) and $7.4 \%$ (US). However, this can be misleading when it comes to a comparison with the Middle East. The methods and frequency of smoking should be taken into account when drawing conclusions about tobacco exposure, because Polish students had a tendency to smoke only occasionally (several times a month).

A cross-sectional study of secondary school students in Saudi Arabia (participants aged 15-19 years) reported that $21.7 \%$ were current smokers in 2012 [11]. Our study from 2011 revealed this percentage as $38.7 \%$ in Poland $(18.2 \%$ smoked both WPs and cigarettes, Figure 1).

A complex comparison between countries of cigarette and/or WP smokers is difficult due to the various presentations of studied groups in papers. However, we can say that the number of cigarette and/or WP smokers in Poland is rather high when compared to other countries. This is surprising given that there is no population of Middle Eastern descent in Poland.

In conclusion, the prevalence of tobacco smoking among Polish youths is high. Youths more often smoke cigarettes and stick with this form of tobacco consumption. WTS was found to be the second most popular form of consumption after cigarette smoking. Moreover, young smokers use various tobacco products and drugs in WPs, and drink alcohol during smoking sessions. More than $45 \%$ of young people in Poland have tried smoking WPs at least once, and more than $20 \%$ of them do it repeatedly. Males tend to be more susceptible to the factors that encourage smoking. The number of men who smoke is almost two times higher than the number of women who smoke. The other important factor influencing this habit is place of residence. Those living in urban areas were twice as likely to smoke as their counterparts in rural areas. An influence of cigarette smoking on WTS was not observed. Many young people try WP smoking without previous experience with cigarettes. Few young people participate in anti-smoking programs. Unfortunately, these programs usually focus on the harmful effects of cigarette smoking and do not give information on WP smoking.

\section{Conflict of interest}

The author declares no conflict of interest.

\section{References}

1. Asfar T, Al Ali R, Rastam S, Maziak W, Ward KD. Behavioral cessation treatment of waterpipe smoking: the first pilot randomized controlled trial. Addict Behav 2014; 39: 1066-74.

2. Shihadeh A, Schubert J, Klaiany J, El Sabban M, Luch A, Saliba NA. Toxicant content, physical properties and biological activity of waterpipe tobacco smoke and its tobacco-free alternatives. Tob Control 2015; 24 Suppl 1: i22-30.

3. Aslam HM, Saleem S, German S, Qureshi WA. Harmful effects of shisha: literature review. Int Arch Med 2014; 7: 16.

4. El-Zaatari ZM, Chami HA, Zaatari GS. Health effects associated with waterpipe smoking. Tob Control 2015; 24 Suppl 1: i31-43.

5. AkI EA, Gunukula SK, Aleem S, et al. The prevalence of waterpipe tobacco smoking among the general and specific populations: a systematic review. BMC Public Health 2011; 11: 244

6. Soule EK, Lipato T, Eissenberg T. Waterpipe tobacco smoking: a new smoking epidemic among the young? Curr Pulmonol Rep 2015; 4: 163-72.

7. Maziak W, Taleb ZB, Bahelah R, et al. The global epidemiology of waterpipe smoking. Tob Control 2015; 24 Suppl 1: i3-12.

8. Eissenberg T, Shihadeh A. Waterpipe tobacco and cigarette smoking: direct comparison of toxicant exposure. Am J Prev Med 2009; 37: 518-23. 
9. Shihadeh A, Saleh R. Polycyclic aromatic hydrocarbons, carbon monoxide, "tar", and nicotine in the mainstream smoke aerosol of the narghile water pipe. Food Chem Toxicol 2005; 43: 655-61.

10. Haddad L, Kelly DL, Weglicki LS, Barnett TE, Ferrell AV, Ghadban R. A systematic review of effects of waterpipe smoking on cardiovascular and respiratory health outcomes. Tob Use Insights 2016; 9: 13-28.

11. Aboaziza E, Eissenberg T. Waterpipe tobacco smoking what is the evidence that it supports nicotine/tobacco dependence? Tob Control 2015; 24 Suppl 1: i44-53.

12. Athamneh L, Sansgiry SS, Essien EJ, Abughosh S. Predictors of intention to quit waterpipe smoking: a survey of arab americans in houston, Texas. J Addict 2015; 2015: 575479.

13. St Helen G, Benowitz NL, Dains KM, Havel C, Peng M Jacob $P 3^{\text {rd }}$. Nicotine and carcinogen exposure after water pipe smoking in hookah bars. Cancer Epidemiol Biomarkers Prev 2014; 23: 1055-66.

14. Moon KA, Magid H, Torrey C, et al. Secondhand smoke in waterpipe tobacco venues in Istanbul, Moscow, and Cairo. Environ Res 2015; 142: 568-74.

15. Jawad M, El Kadi L, Mugharbil S, Nakkash R. Waterpipe tobacco smoking legislation and policy enactment: a global analysis. Tob Control 2015; 24 Suppl 1: i60-5.

16. Jawad M, Nakkash RT, Hawkins B, Akl EA. Waterpipe industry products and marketing strategies: analysis of an industry trade exhibition. Tob Control 2015; 24: e275-9.

17. Sterling KL, Fryer CS, Majeed B, Duong MM. Promotion of waterpipe tobacco use, its variants and accessories in young adult newspapers: a content analysis of message portrayal. Health Educ Res 2015; 30: 152-61.

18. Romanowicz-Makowska H, Smolarz B, Gajecka M, et al. Polymorphism of the DNA repair genes RAD51 and XRCC2 in smoking- and drinking-related laryngeal cancer in a Polish population. Arch Med Sci 2012; 8: 1065-75.

19. Primack BA, Shensa A, Kim KH, et al. Waterpipe smok ing among U.S. university students. Nicotine Tob Res 2013; 15: 29-35.

20. Jawad M, Jawad S, Mehdi A, Sardar A, Jawad AM, Hamilton FL. A qualitative analysis among regular waterpipe tobacco smokers in London universities. Int J Tuberc Lung Dis 2013; 17: 1364-9.

21. Jarrett T, Blosnich J, Tworek C, Horn K. Hookah use among U.S. college students: results from the National College Health Assessment II. Nicotine Tob Res 2012; 14: 1145-53

22. Awan KH, Alrshedan A, Al Kahtani M, Patil S. Waterpipe smoking among health sciences university students: knowledge, attitude and patterns of use. Saudi Dent J 2016; 28: 189-93.

23. Amin TT, Amr MA, Zaza BO, Kaliyadan F. Predictors of waterpipe smoking among secondary school adolescents in Al Hassa, Saudi Arabia. Int J Behav Med 2012; 19: 324-35.

24. Jawad M, Power G. Prevalence, correlates and patterns of waterpipe smoking among secondary school students in southeast London: a cross-sectional study. BMC Public Health 2016; 16: 108.

25. Alzyoud S, Weglicki LS, Kheirallah KA, Haddad L, Alhawamdeh KA. Waterpipe smoking among middle and high school Jordanian students: patterns and predictors. Int J Environ Res Public Health 2013; 10: 7068-82.

26. Central Statistic Office of Poland. Demographic Yearbook of Poland 2010; 2010. Available at: http://wwwstatgovpl/cps/rde/xbcr/gus/PUBL_rs_rocznik_demograficzny_2010pdf
27. Global Adult Tobacco Survey (GATS) Poland 2009-2010; 2010. Available at: http://wwwwhoint/tobacco/surveillance/en tfi gats poland report 2010pdf

28. Global Youth Tobacco Survey (GYTS) Poland; 2003. Available at: http://appsnccdcdcgov/gtssdata/Ancillary/ DataReportsaspx?CAID $=1$

29. Jassem J, Przewozniak K, Zatonski W. Tobacco contro in Poland-successes and challenges. Transl Lung Cancer Res 2014; 3: 280-5.

30. Zatoński M, Przewoźniak K, Jaworski M. The significance and impact of the Polish anti-tobacco Law. J Health Inequal 2016; 2: 32-5.

31. Mojs EH, Warchol-Biedermann K, Glowacka MD, Strzelecki W, Ziemska B, Samborski W. Are students prone to depression and suicidal thoughts? Arch Med Sci 2015; 11: 605-11.

32. Goniewicz ML, Zielinska-Danch W. Electronic cigarette use among teenagers and young adults in Poland. Pediatrics 2012; 130: e879-85. 